\title{
Pessoas transgêneras como condição de vida precária e corpos abjetos na literatura: análise judicial dos casos RE 670.422/RS, RE 845.779/SC e a ADPF 527
}

Transgender people as precarious living conditions and abject bodies in the literature: judicial analysis of Brasilian cases RE 670.422/RS, RE 845.779/SC e a ADPF 527

\author{
Antonio Marcos Quinupa ${ }^{1}$ \\ Universidade de São Paulo (São Paulo, São Paulo, Brasil) \\ quinupa@yahoo.com.br
}

Recebido: 22.02 .2020

Aprovado: 26.04 .2020

\begin{abstract}
Resumo
$\mathrm{O}$ artigo reflete a impossibilidade de um estudo comparado entre a Literatura Brasileira e a Literatura Cubana no que concerne às pessoas transgêneras; e às demais pessoas gênero-divergentes. Trabalha a partir da análise do grau de erudição que o texto "Máscaras", do escritor Cubano Leonardo Padura. Apresenta o repertório do autor em torno do termo das pessoas transe aponta que na Literatura Brasileira algo similar não exista. Para não nos furtarmos do estudo comparado far-se-á análise do caso de Verônica Bolina. Para compor a análise do caso busca-se o entendimento judicial proferido às pessoas transgêneras nos seguintes casos: RE 670.422/RS, RE 845.779/SC e a ADPF 527 que suscitam a discussão, pari passu, ao texto literário, qual seja; distinção do que seja sexo, gênero, orientação sexual e identidade de gênero.
\end{abstract}

Palavras-chave: pessoas transgêneras; literatura brasileira; literatura cubana; sistema prisional.

\footnotetext{
Abstract

This article aims to reflect on the impossibility of a comparative study between Brazilian Literature and Cuban Literature with regard to transgender people; and other gender-divergent people. The degree of erudition that the text "Masks", by Cuban writer Leonardo Padura presents, the repertoire around the term of trans people means that there is nothing similar in Brazilian literature. In order not to shy away from the comparative study, the case of Verônica Bolina will be analyzed. To compose the analysis of the case, we will seek the judicial understanding handed down to transgender people in the hard cases RE 670.422 / RS, RE 845.779 / SC and ADPF 527

Como citar esse artigo: QUINUPA, Antonio Marcos. Pessoas transgêneras como condição de vida precária e corpos abjetos na literatura: análise judicial dos casos RE 670.422/RS, RE 845.779/SC e a ADPF 527. Revista Brasileira de Pesquisa Jurídica, Avaré, v. 1, n. 2, p. 47-62, maio/ago. 2020.

1 Mestre em Direito pelo Centro Universitário Internacional (Uninter). Linha de Pesquisa Teoria e História da Jurisdição. Bacharel em Direito (Uninter) e Licenciado em Letras (UTP). Especialista em Literatura Brasileira e História Nacional (UTFPR). Integrante da ONG Transgrupo Marcela Prado. Membro da Comissão de Diversidade Sexual e de Gênero e da Comissão de Estudos sobre Violência de Gênero da OABPR. Membro do Conselho Penitenciário da Secretaria de Segurança Pública do Estado do Paraná. Aluno do Aluno do PROLAM - USP, Literatura e História da América Latina.
} 
that give rise to the discussion, pari passu, to the literary text, whatever; distinction of what is sex, gender, sexual orientation and gender identity.

Keywords: transgender people; Brazilian Literature; Cuban Literature; prison system.

\section{Introdução}

Discorrer sobre as pessoas transgêneras no Brasil nos remete à sistematização do que seja o movimento LGBT, como se constitui e como as tensões são travadas diariamente para que cada identidade seja/esteja comtemplada. Nos últimos quarenta anos o movimento LGBT tem pautado suas reivindicações sociopolíticas e jurídicas e empreendido esforços para abranger o maior número possível de pessoas gênerodivergentes.

Ultimamente a sigla utilizada, para representar o movimento, varia entre LGBTTIAQ e LGBTI+. A sigla LGBTTIAQ compreende as pessoas lésbicas, gays, bissexuais, travestis, transexuais, intersexuais, assexuadas e queer, já a LGBTI+ compreende lésbicas, gays, bissexuais, transexuais, intersexuais e + como espaço a ser ocupado por novas subjetividades.

É na seara jurídica que o movimento tem encontrado combustível na busca de condições de possibilidades para tornar a vida das pessoas transgêneras vivíveis, em uma perspectiva do processo civilizatório in progress. Nessa perspectiva analisamos casos que chegaram ao Supremo Tribunal Federal - STF tomados como hard cases, nas palavras do filósofo Luiz Fernando Coelho:

[...] têm sido definidos como envolvendo conflitos judiciais que admitem mais de uma solução, seja em virtude de vagueza ou obscuridade da norma aplicável, seja em face da existência de duas ou mais igualmente aplicável, seja ainda em face de lacunidade da legislação (COELHO, 2018, p. 21).

\section{Recurso Especial 670.422/RS}

Apesar de não ter sido possível mapear o trâmite do pedido de "ALTERAÇÃO DE REGISTRO CIVIL" ajuizado por S.T.C., por estar em segredo de justiça. Dessa forma as ilações são feitas a partir do voto do E. Relator, Ministro José Antonio Dias Toffoli, do Supremo Tribunal Federal - STF. Do inteiro teor do acórdão e do parecer da 
Procuradoria-Geral da República, depreende-se que o Juízo de primeiro grau atendeu parcialmente o pedido, retificando o prenome e não retificando o designativo de sexo, manifestando ainda a necessidade de a pessoa requerente realizar a cirurgia de redesignação sexual para o deferimento da alteração do assentamento civil relativo ao sexo, bem como averbação no registro de nascimento sua condição de transexual. A pessoa autora da ação interpõe recurso de apelação e mesmo o Parquet se manifestando pelo improvimento do recurso ao Juízo da $8^{\text {a }}$ Câmara do Cível do E. Tribunal de Justiça do Estado do Rio Grande do Sul, por maioria, deu provimento ao recurso por entender a impossibilidade de anotação de retificação de designativo de sexo como transexual. Da decisão a pessoa autora opôs embargos de declaração, não acolhido pelo E. Tribunal, restando à mesma interpor Recurso Extraordinário conforme ementa:

\begin{abstract}
Direito constitucional e civil. Registros públicos. Registro civil das pessoas naturais. Alteração do assento de nascimento. Retificação do nome e do gênero sexual. Utilização do termo transexual no registro civil. O conteúdo jurídico do direito à autodeterminação sexual. Discussão acerca dos princípios da personalidade, dignidade da pessoa humana, intimidade, saúde, entre outros, e a sua convivência com princípios da publicidade e da veracidade dos registros públicos. Presença de repercussão geral ${ }^{2}$.
\end{abstract}

Alega a pessoa autora violação do princípio da dignidade humana e os arts. $3^{\circ}$ (direitos fundamentais), inciso IV (princípio da vedação à discriminação), $5^{\circ}$, inciso (princípio da igualdade) $\mathrm{X}$ (princípio da liberdade e da privacidade) e $6^{\circ}$ (direitos sociais $^{3}$ ) da Constituição Federal:

S.T.C. interpõe recurso extraordinário, com fundamento na alínea a, do permissivo constitucional, contra acórdão proferido pela Oitava Câmara Cível do Tribunal de Justiça do Estado do Rio Grande do Sul assim ementado: Apelação cível. Registro civil. Alteração do assento de nascimento. Troca de nome e sexo. À equação do presente pertinente a averbação no assento de nascimento do (a) recorrente sua condição de transexual. Aplicação dos princípios da publicidade e da veracidade dos registros públicos, pois estes devem corresponder à realidade fenomênica do mundo, sobretudo para resguardo de direitos e interesses de terceiros. Por maioria, deu provimento em parte, vencido o relator.

\footnotetext{
2 Tema 761: É possível a alteração de gênero no registro civil de transexual, mesmo sem a realização de procedimento cirúrgico de adequação de sexo, sendo vedada a inclusão, ainda que sigilosa, do termo "transexual" ou do gênero biológico nos respectivos assentos.

3 Ao anunciar os direitos sociais como princípio a autora da ação vislumbra, com a procedência do pedido, efeito erga omnes, para todas as pessoas transexuais.
} 
Acrescenta ainda que "o direito do transexual de ter no seu assento de nascimento o registro do sexo a que pertence deve prevalecer em respeito à dignidade da pessoa humana e ao direito à felicidade ${ }^{4}$, , afirma que a deliberação da Corte (STF) repercutirá não apenas na esfera jurídica do recorrente, mas de todos os transexuais [sic] que buscam adequar sua identidade de sexo à sua identidade de gênero, mesmo sem a realização de todos os procedimentos cirúrgicos de redesignação, aduzindo que o que se busca é um precedente histórico de enorme significado e repercussão, não só jurídica, mas também de inegável repercussão social.

O parecer da PGR propõe a fixação da tese de que "é possível a alteração de gênero no registro civil de transexual, mesmo sem a realização de procedimento cirúrgico de adequação de sexo, sendo vedada a inclusão, ainda que sigilosa, do termo "transexual" ou do sexo biológico nos respectivos assentos em total consonância com o pedido distribuído por S.T.C.

\section{Recurso Especial 845.779/SC}

Simultaneamente ao trâmite do RE 670.422 , em que as pessoas trans eram submetidas ao escrutínio do discurso médico, para validar o discurso jurídico, estava sendo pautado o RE 845.779/SC. Nele foi apresentado, na petição amicus curiae, o entendimento de pessoas transgêneras como transgressão da norma binária de gênero.

Para se afirmar o entendimento de transgênero como transgressão da norma binaria de gênero masculino/feminino, unicamente reconhecido pelo direito, na petição foi discorrido sobre a celeuma do que seja sexo, gênero, orientação sexual e identidade de gênero fundamentada no dispositivo da sexualidade foucaultiano:

\footnotetext{
A sexualidade é o nome que se pode dar a um dispositivo histórico: não à realidade subterrânea que se apreende com dificuldade, mas à grande rede da superfície em que a estimulação dos corpos, a intensificação dos prazeres, a incitação ao discurso, à formação dos conhecimentos, o reforço dos controles e das resistências, encadeiam-se uns aos outros, segundo algumas grandes estratégias de saber e de poder. (FOUCAULT, 1988, p. 116-117).
}

Quando falamos em sexo, o primeiro significado que se nos apresenta é o que está vinculado ao biológico ou genital. Todavia, sexo nos remete somente às diferenças

\footnotetext{
${ }^{4}$ Conforme parecer n. No 158560/2015 do Ministério Público Federal - ASJCIV/SAJ/PGR.
} 
genéticas, fisiológicas e anatômicas entre a genitália do macho e da fêmea das espécies sexuadas (LANZ, 2015, p. 40), ao passo que gênero é categoria de análise sociológica, política e histórica. É dispositivo de controle social, erigido, sobretudo juridicamente, para instituir normas de conduta, haja vista a produção jurídica da existência de duas (somente duas) categorias de gênero, homem ou mulher ou masculino e feminino, que são atribuídas ao nascer e que se inscrevem na certidão de nascimento.

No entanto, a orientação sexual, como a própria expressão aponta, é para onde o desejo é orientado, está vinculada ao desejo erótico e afetivo da pessoa relativamente a quem ela namora ou mantém relação sexual. Por identidade de gênero tomamos possibilidade uma pessoa constituir-se de forma não prescrita pelo binarismo de gênero: a condição de ser homem ou mulher não está diretamente vinculada ao sexo que foi designado ao nascer e, necessariamente, a orientação sexual não está vinculada ao sexo biológico.

Quando uma pessoa se autodenomina travesti ou transexual, ela não está reivindicando para si a apropriação de ser homem ou mulher. Está exatamente problematizando o cistema ${ }^{5}$, que atribui às pessoas que nascem com o aparato biológico masculino a consonância em constituir-se como homem, da mesma forma como a pessoa que nasce com o aparato biológico feminino em constituir-se como mulher.

$O$ entendimento de que a identidade de gênero e a orientação sexual correspondem ao sexo designado no nascimento é disseminado pela filósofa Judith Butler como heteronormatividade (BUTLER, 2010, p. 24), de forma que a manifestação de uma orientação sexual e identidade de gênero que não estejam vinculadas ao sexo biológico (atribuído ao nascer) causa uma pane no cistema heteronormativo.

Para além do reconhecimento do direito à mudança de prenome e designativo sexual das pessoas transgêneras sem necessidade de cirurgia de transgenitalização e de laudos ficou assentado que o pedido de retificação de prenome e sexo das pessoas transgêneras de ação extrajudicial ${ }^{6}$.

\footnotetext{
${ }^{5} \mathrm{O}$ cistema que estamos denominando decorre da definição de pessoas cis, como apresentado pelo movimento transfeminista: pessoa cis é pessoa cujo sexo designado ao nascer + sentimento interno/subjetivo de sexo + gênero designado ao nascer + sentimento interno/subjetivo de gênero estão "alinhados" ou "deste mesmo lado" - o prefixo cis em latim significa "deste lado" (e não do outro), uma pessoa cis pode ser tanto cissexual e cisgênera. Disponível em: $\langle$ https://bit.ly/3lpHChT $\rangle$ Acesso em 22 de nov de 2020.

${ }^{6}$ Por mais que a Certidão de Julgamento das ações conjuntas, RE 670.422/RS e ADI 4275, que viabilizou o pedido de retificação de prenome e designativo sexual extrajudicialmente gerasse efeito, erga omnes,
} 


\title{
4. Arguição de Descumprimento de Preceito Fundamental - ADPF 527
}

A ADPF 527 versa sobre o acolhimento da comunidade LGBT, especialmente sobre a possibilidade de pessoas transgêneras, vítimas de maior vulnerabilidade, serem alocadas de acordo com sua identidade de gênero no sistema prisional.

A ação foi proposta pela Associação Brasileira de Gays, Lésbicas, Bissexuais, Travestis, Transexuais e Intersexos - ABGLT, e discute normas que a associação afirma serem descumpridas da Resolução Conjunta da Presidência da República e do Conselho de Combate à Discriminação, Portaria n. 1, de 14 de abril de 2014 , no art. $3^{\circ}, \S \S 1^{\circ}, 2^{\circ}$ e art. $4^{\circ}$, caput e parágrafo único, in verbis:

\begin{abstract}
Art. $3^{\circ}$ - Às travestis e aos gays privados de liberdade em unidades prisionais masculinas, considerando a sua segurança e especial vulnerabilidade, deverão ser oferecidos espaços de vivências específicas. $\S 1^{\circ}$ - Os espaços para essa população não devem se destinar à aplicação de medida disciplinar ou de qualquer método coercitivo. $\S 2^{\circ}$ - A transferência da pessoa presa para o espaço de vivência específico ficará condicionada à sua expressa manifestação de vontade. Art. $4^{\circ}$ - As pessoas transexuais masculinas e femininas devem ser encaminhadas para as unidades prisionais femininas. Parágrafo único - Às mulheres transexuais deverá ser garantido tratamento isonômico ao das demais mulheres em privação de liberdade.
\end{abstract}

Há que se observar que a própria Resolução Conjunta apresenta um entendimento controvertido, para não dizer comprometedor, quanto à orientação sexual e identidade de gênero. Apresenta o entendimento de que travestis e gays estão dentro da mesma matriz de inteligibilidade quanto à constituição de suas subjetividades: "às travestis e aos gays privados de liberdade em unidades prisionais masculinas". Conforme apresentado na análise do RE 845.779, identidade de gênero está para as pessoas transgêneras que subvertem a norma jurídica de gênero (notadamente englobando as travestis), assim como a orientação sexual está para gays, lésbicas e bissexuais.

Dessa forma o melhor entendimento dispensado às travestis seria acomodá-las no ambiente prisional feminino por sua identidade de gênero, sua autopercepção

em todo Território Nacional na data de 01.03.2018, alguns entes federados aguardaram o Provimento do Conselho Nacional de Justiça - CNJ, a exemplo do Estado do Paraná. O Provimento $\mathrm{n}^{\mathbf{o}} 73$ foi publicado na data de 28.06.2018. 
enquanto identidade feminina, não como está sendo lida pelo sistema prisional por sua genitália, direcionando-a ao espaço prisional masculino.

Contudo, em decisão da medida cautelar da ADPF 527, o relator defere parcialmente o pedido, determinando que as pessoas transexuais femininas sejam transferidas para os presídios femininos, não estendendo a proteção às demais pessoas transgêneras encarceradas, em total dissonância com os mecanismos de proteção pelos órgãos internacionais como a Declaração Universal dos Direitos Humanos, nos arts. $2^{\circ}$, $3^{\circ}$ e $5^{\circ 7}$ e aos Princípios de Yogyakarta ${ }^{8}$, que versam, especificamente sobre orientação sexual e identidade de gênero. A dissonância pode ser vista também em relação a dispositivos da Constituição Federal de 1988, que prega a igualdade e o combate à discriminação.

\section{A Literatura pela lente do discurso jurídico}

Segundo autores como Foucault, entendem que a sexualidade "demarca um conjunto decididamente heterogêneo que engloba discursos, instituições, organizações arquitetônicas, decisões regulamentares, leis, medidas administrativas, enunciados científicos, proposições filosóficas, morais, filantrópicas (FOUCAULT, 1979, p.244).”

Neste contexto as pessoas transgêneras estão inseridas, no jogo de saber-poder propalado pelo exame da verdade que se configurou desde a Idade Média, em que as figuras eram postas como monstros humanos e por estarem submetidas à lei (da natureza) como consequência da noção jurídica torna-se um "registro duplo, infração às leis e em sua existência mesma (FOUCAULT, 2001, p. 69).”

\footnotetext{
${ }^{7}$ Art. $2^{\text {o }}$ - 1. Todo ser humano tem capacidade para gozar os direitos e as liberdades estabelecidas nesta Declaração, sem distinção de qualquer espécie, seja de raça, cor, sexo, idioma, religião, opinião política ou de qualquer outra natureza, origem nacional ou social, riqueza, nascimento, ou qualquer outra condição. Art. $3^{\circ}$ - Todo ser humano tem direito à vida, a liberdade e à segurança pessoal. Art. $5^{\circ}$ Ninguém será submetido à tortura nem a tratamento ou castigo cruel, desumano ou degradante .

8 Por ocasião da comemoração dos 60 anos da Declaração dos Direitos Humanos os Princípios de Yogyakarta foram apresentados como uma carta global para os direitos LGBT, a 26 de março de 2007 perante o Conselho de Direitos Humanos das Nações Unidas em Genebra. Estes princípios não foram adotados pelos Estados em tratado, e, portanto, não constituem, por só, um instrumento vinculativo do direito internacional dos direitos humanos. No entanto, os autores pretendem que os Princípios de Yogyakarta são adotados como uma norma universal, isto é, uma norma legal internacional obrigatória para os Estados, a que alguns países têm reservas expressas. Na Assembleia Geral da Organização das Nações Unidas, em Nova York, em 18 de dezembro de 2008, o Brasil assina a recomendação à Orientação Sexual e Identidade de Gênero.
} 
Submetem-se ao saber biológico-jurídico, vemos nascer, portanto, o conhecimento médico legitimado pelo discurso jurídico para falar sobre essas pessoas que serão inseridas na categoria de monstros, anormais, abjetos: os hermafroditas, que serão "executados, queimados, suas cinzas jogadas ao vento (FOUCAULT, 2001, p. 83)." Podem-se citar como exemplos os casos de Antide Collas, Marie Lemarcis e Anne Grandjean.

Antide Collas, hermafrodita do séc. XVI, que por ser diagnosticada em possuir dois sexos, foi condenada à fogueira:

[...] após um exame, os médicos concluíram que, de fato, aquele indivíduo possuía dois sexos porque tivera relações com Satanás e que as relações com Satanás é que haviam acrescentado a seu sexo primitivo um segundo sexo. Torturado, o hermafrodita foi queimado vivo. (FOUCAULT, 2001, p. 84).

Marie Lemarcis, hermafrodita do século XVII, que se identificava como homem e adotara o nome de Marin Lemarcis e vivia com sua esposa, entretanto foi diagnosticada como mulher e condenada a ser enforcada, queimada e suas cinzas jogadas ao vento, por sorte seu recurso foi atendido e os peritos identificaram-na como mulher, sem nenhum sinal de virilidade e foi condenada a vestir/portar como mulher e não mais ter relações; fora condenada a ser enforcada, queimada e suas cinzas jogadas ao vento, por sorte, da pena capital houve recurso e tendo sido acolhido consta no veredicto:

Solta a mulher, proscreve-lhe simplesmente que mantenha as roupas femininas e proíbe-a de morar com qualquer outra pessoa de um ou outro sexo, "sob pena de vida". Logo, interdição de qualquer relação sexual, mas nenhuma condenação por hermafroditismo, por natureza de hermafroditismo, e nenhuma condenação tampouco pelo fato de ter vivido com uma mulher, embora, ao que parece, seu sexo dominante fosse o feminino. (FOUCAULT, 2001, p. 85).

No final do séc. XVIII, Anne Grandjean fora batizada como menina, sua infância vivera como menina, na adolescência sentira atração por meninas e assumira a identidade masculina e casa-se com Françoise Lambert. Denunciada foi levada a juízo, e, de novo, foi diagnosticada como mulher, condenada a viver como mulher e proibida do convívio de Françoise Lambert. Ela “é libertada, com a obrigação de usar 
indumentárias femininas e proibição de frequentar Françoise Lambert ou qualquer outra mulher (FOUCAULT, 2001, p.90)."

Pelo dispositivo da sexualidade, no entendimento dessa situação histórica, o tratamento da construção da percepção das pessoas transgêneras como monstruosidade vai do "jurídico-natural" ao "jurídico-moral", incidindo na "criminalidade pura e simples (FOUCAULT, 2001, 92)."

É nessa perspectiva que emergem grande parte dos casos que envolvam pessoas transgêneras. Tomemos como exemplo o caso de Verônica Bolina. Em 2015 a face desfigurada de uma travesti estampou uma série de notícias e virou tema de campanhas por direitos de pessoas trans.

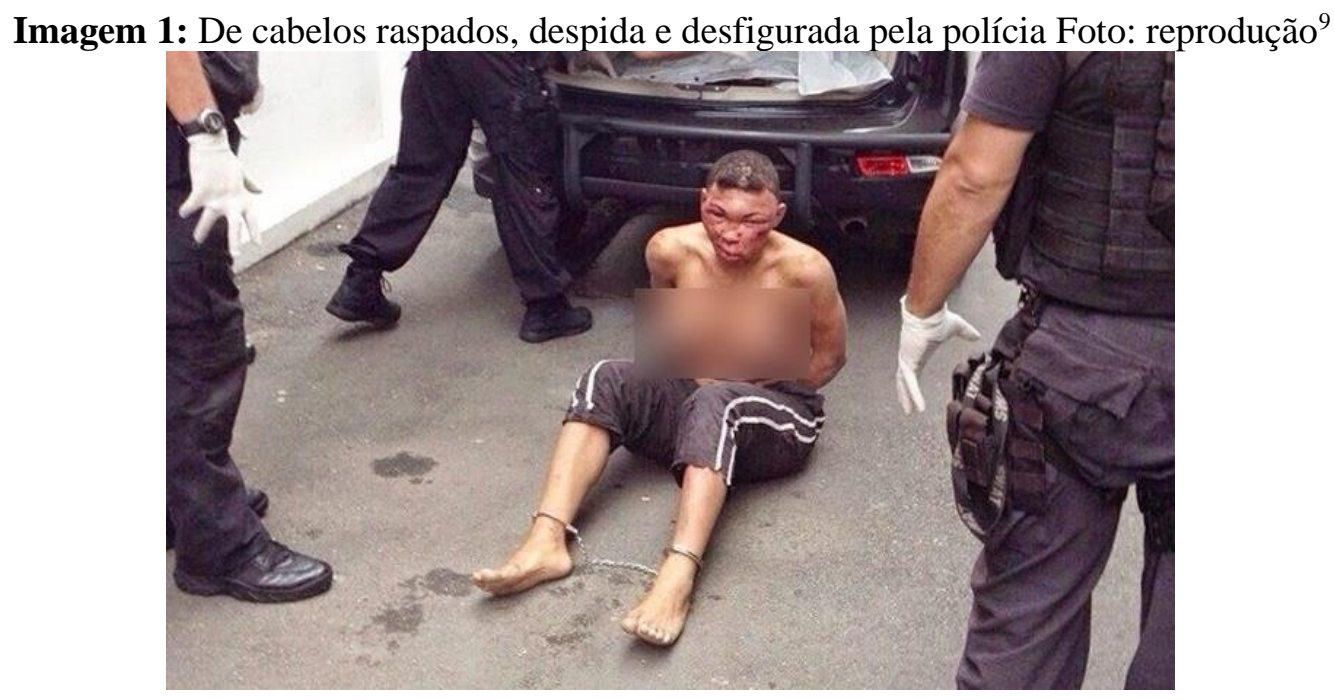

A face é de Verônica Bolina, travesti presa e, em situação psicológica instável, colocada em uma cela com onze homens e em seguida em outra com três homens, onde começaram as agressões, devidas a conflito com os presos por ser travesti. Verônica narra que, em seguida, reagindo a uma agressão de um policial, mordeu a orelha dele chegando a arrancar um pedaço e que, a partir de então foi submetida a formas de tortura parte de policiais que incluem ameaças, xingamentos transfóbicos, chutes e socos, spray de pimenta, tiros e introdução de um cabo de vassoura em seu ânus. As

\footnotetext{
${ }^{9}$ Fonte: Domínio Público. Disponível em: < https://bit.ly/3lki4Ti> Acesso em: 30 jan. 2020.
} 
fotos de Verônica com os seios e parte das pernas a mostra, machucada e torturada se proliferaram pela internet.

Após retornar à prisão Verônica relata, ainda, ter sido coagida a gravar um áudio negando a tortura e afirmando não querer ser usada para fins políticos. Nos autos do processo da apuração de violação de direitos humanos, agressão e tortura de Verônica do Conselho Estadual dos Direitos da Pessoa Humana (CONDEPE) de São Paulo são levantados importantes questionamentos acerca, dentre outros fatores, dos motivos para uma presa em estado de confusão mental ter sido alocada em uma cela com onze homens, da necessidade de força policial com tal intensidade usada contra ela, da obtenção das imagens de Verônica e da situação de outras presas travestis e transexuais em situações comparáveis.

Embora em São Paulo o Decreto 55.888/2010 determine que o direito à identidade de gênero deva ser respeitado e que pessoas transgêneras devem ser tratadas por servidores públicos com respeito ao nome e aos pronomes escolhidos e a Resolução Conjunta da Presidência da República e do Conselho de Combate à Discriminação, Portaria n. 1, de 14 de abril de 2014 estabeleça que mesmo em privação de liberdade a identidade de gênero deve ser respeitada, Verônica teve todos esses direitos violados. Além da flagrante violência física, seu corpo exposto e seus longos cabelos cortados feriram sua identidade.

A maior parte das formas de violência descritas foram praticadas intencionalmente não só pelos agentes estatais autores como também com a conivência dos demais agentes estatais presentes.

Trata-se de um caso tipificado, quando normalmente os casos relacionados às pessoas transgêneras veem à tona de forma subnotificada. O que demonstra o exercício quixotesco para uma virada, para que essas pessoas sejam retiradas desse lugar de marginalização e acedam um espaço de representação, ao que nos propomos aqui, por exemplo, da literatura.

Para capturar o conceito de literatura recorremos ao que Megale apresenta, etimologicamente, que "a palavra vem do latim littera, ae, que quer dizer letra. Do plural litterae, arum (pluralia tantum), significando carta ou cartas, ou ainda, toda espécie de escritos, é que proveio sentido geral de cultura, instrução, atribuído à literatura (MEGALE, 1975, p.1)", para Eagleton Terry podemos "defini-la como a 
escrita "imaginativa", no sentido da ficção (EAGLETON, 2006)." Segundo Anatol Rosenfeld "pensamos no que tradicionalmente se costuma chamar "belas letras" ou "beletrística" (ROSENFELD, 2014, p. 11)."

Nossa justificativa em eleger o texto "Máscaras" como análise vem na esteira do que o Professor José Elias Pinheiro Neto propõe ao analisar o texto de Carlos Augusto de Figueiredo Monteiro, "Mapa e a Trama" ao observar que "o processo de construção do conhecimento pode ser dado pelo sujeito da trama, e eles carregam consigo a subjetividade do conhecimento (NETO, 2018, p. 136) ${ }^{10}$ ", qual seja, a justificativa que o personagem Mario Conde apresenta para escrever sobre o tema: "[Já] temos até travestis assassinados, somos quase um país desenvolvido (PADURA, 2016, p. 30).”

Ao debruçarmos-nos na análise da condição das pessoas transgêneras, a partir da perspectiva do discurso jurídico, aproximando-a da literatura, sobretudo da literatura canônica, da envergadura do escritor Leonardo Padura, não pensamos de maneira teleológica, nem mesmo para revitimizá-las, mas para entendermos porque no Brasil essas pessoas ocupam o lugar de marginalizadas, porque ainda são capturadas pelo discurso psi patologizante, corpos abjetos (FOUCAULT, 201), haja vista o escrutínio que as pessoas trans se submetem ao requererem pedido de retificação de prenome e sexo. Se a condição trans não faz esse movimento, sair do espaço que a marginalizam, e ocupar o status (canônico) da literatura, que em tese expressaria o reflexo da sociedade, no caso da Literatura Cubana que deu um passo no processo civilizatório, é porque temo um longo caminho a percorrer:

\begin{abstract}
O processo de evolução da literatura é lento e gradativo, seguindo um ritmo dialético: a "tese" é constituída pelo nascimento de formas novas, aptas a expressar uma diferente visão da realidade; a "antítese" é a afirmação consciente, o estágio de maturidade desse novo sentir, expresso por sistema de normas em oposição ao código artístico e ideológico do período anterior; a "síntese" é determinada pela transformação num novo período: as formas literárias de uma época, chegada ao apogeu, cristalizam-se, criam automatismos, e a conseqüente repetição de estereótipos estéticos e espirituais privam as produções artísticas de seu caráter de originalidade e de novidade (D'ONOFRIO, 2000, P. 97).
\end{abstract}

No romance, o policial Mario Conde é compelido a investigar o assassinato do filho do diplomata Cubano Faustino Arayán, Alexis, que fora estrangulado no Bosque de Havana. A trama gira em torno da investigação para deflagrar o assassinato e no

\footnotetext{
${ }^{10}$ Disponível em: < https://bit.ly/36qSJ5M> Acesso em: 30 de nov de 2020.
} 
trajeto o investigador submerge em um mundo ainda marginalizado, que vai desde o espaço que esse corpo ocupa no mundo aos espaços (físico-territoriais) de Cuba, passando por seus dramas e conflitos, tanto pessoais quanto familiares. Nessa trajetória, também, o personagem conjuga seus próprios dramas e é arrastado para o caso.

Alexis ora é lido como gay, como travesti ou até mesmo como transexual. Nas idas e vindas da investigação, a todo o momento, era etiquetado pelos papéis de gênero, "um travesti morto no Bosque de Havana", "Um rosto de mulher, violáceo e inchado, arrematava a figura", "mulher sem os benefícios da natureza, toda engalanada de vermelho", "o travesti não resistiu", "você e ele mantinha relação homossexual”, “o tipo, digo, a tipa, não esperneou", "história escatológica de um veado estrangulado e com duas moedas no cu", "Esse travesti não se vestiu para se exibir nem para sair caçando", "o pai o odiava por ser, bem, por ser veado", "tenho cá para mim que ele era mais mulher do que homem", "o que ele gostaria era de viver numa casa com um homem, que fosse seu marido", "O senhor não pode imaginar o que uma mãe sente quando descobre que seu filho é homossexual...",

Não vamos advogar sobre a orientação sexual ou identidade de gênero de Alexis, mesmo porque quem poderia fazê-la seria ele próprio, o que chama a atenção, e que é recorrente grifarem "um travesti” [sic], tanto em Cuba quanto em Brasil, lá pela pena do escritor, aqui nas reportagens, a dificuldade em conjugar o artigo referente ao gênero. Pela obra podemos observar os espaços que são destinados ás pessoas com orientação sexual e identidade de gênero divergente. Alexis estava fadado a não sobreviver na mansão "de dois andares na Sétima Avenida de Miramar, com um jardim bem cuidado e paredes pintadas de branco brilhante, vidraças milagrosamente intactas na cidade de vidros quebrados e dois automóveis na garagem (PADURA, 2016, p.35)."

Fora abrigado em um "antigo quarto de empregados da residência" do Senhor Alberto Marqués, em que "havia um pequeno banheiro independente, e era possível ter acesso ao quarto sem entrar na casa principal"; todavia para as demais pessoas restavam-lhes a La Rampa ou a El Prado, onde o trottoir das pessoas trans serviram de laboratório de investigação para policial, ou qualquer casa, beco às escuras. Até mesmo nesses becos, onde não se furtavam práticas excusas, sobravam-lhes 'porradas' para os gays que quisessem adentrar: "Aqui o que vale é a lei da selva: respeito é respeito". Primeiro agridem (fisicamente), depois se procuram justificar, impingir qualquer 
estigma, para não admitir e não permitir que de alguma forma sobreviva, mesmo que de programa sexual:

\footnotetext{
"As pessoas o alugam para que cobre por elas: ele tanto cobra dinheiro emprestado como faz qualquer tipo de serviço: uma chifrada no marido, uma caguetagem, qualquer coisa que uma pessoa quiser cobrar de outra. E o cara é profissional no assunto (PADURA, 2016, p. 119)."
}

Alexis sucumbe às adversidades e flerta com a morte, "Mas Alexis sofria muito, sofria por tudo, e se não o tivessem matado eu diria que se suicidou”. Mas suicidar-se como, sendo cristão? Incorrer na duplicidade do pecado imposto pela igreja; em vida viver como 'pervertido', na morte como suicida? Não. Por isso recorre à Escritura Bíblica com a história da Transfiguração:

\footnotetext{
"[no] capítulo 9 de Marcos: "As vestes tornaram-se resplandecentes e sobremodo brancas como nenhum lavanderio na terra as poderia alvejar", e também no 9 de Lucas: "E, enquanto rezava, seu rosto tomou outro aspecto e seu vestido ficou branco e resplandecente" (PADURA, 2016, p. 103).”
}

Travestiu-se de Electra Garrigó, no dia 6 de agosto, festa da Transfiguração para os católicos, e foi de encontro ao seu algoz, ocupar esse espaço; ou não espaço, esse silêncio ensurdecedor, da linguagem; ou da não linguagem, "é que a linguagem é espaço (FOUCAULT, 2005, p 168).”

\section{Considerações finais}

É flagrante o recrudescimento que houve no avanço de garantias de direitos fundamentais das pessoas transgêneras no pequeno lapso temporal entre a decisão do RE 670.422, que colocou o pedido de retificação de prenome nos cartórios, e do pedido de liminar da ADPF 527.

Basta verificar a manifestação teratológica do E. Relator, deixar as travestis no limbo. O julgamento da ADPF não foi pautado ainda, de forma que alguns pedidos de habilitação como amicus curiae estão sendo feito, o que de certa forma ajuda fomentar a discussão, haja vista a inércia legislativa.

No cenário literário as escritas de pessoas transgêneras tem tido um forte movimento com os textos memorialísticos, como as pessoas transgêneras borram as 
fronteiras do binarismo de gênero, borrar as fronteiras da literatura canônica é o próximo passo no processo evolutivo da humanidade, um espaço a ser ocupado.

\section{Referências}

BOBBIO, Norberto. A era dos Direitos. Rio de Janeiro: Elsevier, 2004.

BRASIL. Ministério da Saúde. Redefine e amplia o Processo Transexualizador no Sistema Único de Saúde (SUS). Gabinete do Ministro. Portaria n. 2.803, de 19 de novembro de 2013.

Ficha técnica. Esse material é uma publicação do Projeto: Expressão Trans, executado pelo TMP, por meio do convênio n. 814600/2014, firmado entre a instituição e o Ministério da Saúde;

2008.

Secretaria de atenção à saúde. Portaria n. 457, de 19 de agosto de

BUENO, Cassio Scarpinella. Amicus curiae no processo civil brasileiro: um terceiro enigmático. 2 ed. ver., atual. e ampl. São Paulo: Saraiva, 2008.

BUTLER, Judith P. Problema de gênero: feminismo e subversão da identidade. $3^{\mathrm{a}}$ ed. Rio de Janeiro: Civilização Brasileira, 2010.

CANDIDO, Antonio... [et. al.]. A personagem de ficção. São Paulo: Perspectiva, 2014.

CASTRO, Edgardo. Vocabulário de Foucault: Um percurso por seus temas, conceitos e autores. Belo Horizonte: Autêntica, 2009.

COELHO, Luiz Fernando. Direito constitucional e filosófica da constituição. $4^{\mathrm{a}}$ impr. Curitiba: Juruá, 2017.

Literatura e sociedade: estudos de teoria e história literária. $8^{\mathrm{a}}$ ed. São Paulo: T. A. Queiroz, 2000.

Teoría crítica del derecho. $4^{\mathrm{a}}$ edição. Curitiba: Juruá, 2012.

Conselho Federal de Medicina. Resolução 1652/2002.

CORTÊS, Ana de Mello. Em busca de diálogo e reconhecimento no STF: a atuação como amicus curiae nas causas relativas às pessoas trans. 2018. Dissertação (Mestrado em Direito) - Escola de Direito de São Paulo da Fundação Getúlio Vargas.

D’ONOFRIO, Salvatore. Metodologia do trabalho intelectual. $2^{\mathrm{a}}$ ed. São Paulo: Atlas, 2000 .

EAGLETON, Terry. Teoria da literatura: uma introdução. Tradução Waltensir Dutra, $6^{a}$ ed. São Paulo: Martins Fontes, 2006. 
FOUCAULT, Michel. A verdade e as formas jurídicas. $3^{\mathrm{a}}$ ed. Rio de Janeiro: NAU, 2005.

. As Palavras e as Coisas. 9a ed. São Paulo: Martins Fontes, 2007.

. Os Anormais. $18^{\mathrm{a}}$ ed. São Paulo: Martins Fontes, 2001.

Edições Graal, 1988.

História da Sexualidade I a vontade de saber. $18^{\mathrm{a}}$ ed. Rio de Janeiro: Nascimento da biopolítica. São Paulo: Martins Fontes, 2008.

. Vigiar e Punir. 30ª ed. São Paulo: Vozes, 1999.

HESPANHA, António M. Cultura Jurídica Europeia: síntese de um milênio. Coimbra: Almedina, 2012.

Pluralismo Jurídico e Direito Democrático. São Paulo: Annablume,

2013.

KULICK, Don. Travesti: prostituição, sexo, gênero e cultura no Brasil. Rio de Janeiro: Editora Fiocruz, 2008.

LANZ, Letícia. O Corpo da roupa: a pessoa transgênera entre a transgressão e a conformidade com as normas de gênero. Uma introdução aos Estudos de Transgêneros. Curitiba: Transgente, 2015.

LIMA, Francielle Elisabet Nogueira. Tutela jurídica de pessoas trans: análise crítica a partir do feminismo. Rio de Janeiro: Lumen Juris, 2018.

LOPES, Alice Ribeiro Casemiro. Conhecimento Escolar: ciência e cotidiano. Rio de Janeiro: EdUERJ, 1999.

MACHADO, Roberto. Foucault, a ciência e o saber. $6^{\text {a }}$ ed. Rio de Janeiro: Jorge Zahar, 2006.

2005.

Foucault, a filosofia e a literatura. $3^{\mathrm{a}}$ ed. Rio de Janeiro: Jorge Zahar,

Marcha das Vadias CWB. Disponível em: 〈https://bit.ly/2TvZ0sa〉. Acesso em 28 nov. de 2020.

MEGALE, Heitor. Elementos da teoria literária: ensino de $2^{\circ}$ grau. $2^{\mathrm{a}}$ ed. São Paulo: Editora Nacional, 1975.

PRECIADO, Beatriz. Manifesto contrassexual. São Paulo: n-1 edições, 2014. 
PADURA, Leonardo. Máscaras. Tradução Rosa Freire D’Aguiar, $2^{\mathrm{a}}$ ed. São Paulo: Boitempo, 2016.

Texto Yonqui. España: Espasa Calpe: 2008.

PIMENTEL, Alessandra. O MÉTODO DA ANÁLISE DOCUMENTAL: SEU USO NUMA PESQUISA HISTORIOGRÁFICA. Disponível em: <https://bit.ly/2CcxsgC〉. Acesso em 28 de nov. de 2020.

SANTOS, Boaventura de Sousa. Do pós-moderno ao pós-colonial. E para além de um e de outro. Disponível em: < https://bit.ly/2KPJmUQ>. Acesso em 17 nov de 2020.

SCOOT, Joan Wallach. Gênero: uma categoria de análise útil histórica. Educação \& Realidade. Porto Alegre, vol. 20, nº 2, jul/dez. 1995. 